\title{
Eficácia in vitro de desinfetantes comerciais utilizados no pré e pós-dipping frente a Staphylococcus spp. isolados em rebanhos leiteiros ${ }^{1}$
}

\author{
Ayodhya C. Ramalho ${ }^{2}$, Karla D.A. Soares ${ }^{2}$, Deivisson F. da Silva ${ }^{2}$, Maria Raquel C. \\ Barros $^{2}$, José W. Pinheiro Júnior ${ }^{3}$, Júnior M.B. de Oliveira ${ }^{3}$, Rinaldo A. Mota ${ }^{4}$ \\ e Elizabeth S. de Medeiros ${ }^{2 *}$
}

\begin{abstract}
Ramalho A.C., Soares K.D.A., Silva D.F., Barros M.R.C., Pinheiro Jr. J.W., Oliveira J.M.B., Mota R.A. \& Medeiros E.S. 2012. [In vitro efficacy of commercial disinfectants used in pre- and post-dipping against Staphylococcus spp. isolated from dairy cattle.] Eficácia in vitro de desinfetantes comerciais utilizados no pré e pós-dipping frente a Staphylococcus spp. isolados em rebanhos leiteiros. Pesquisa Veterinária Brasileira 32(12):1285-1288. Departamento de Inspeção de Produtos de Origem Animal, Universidade Federal de Alagoas, Campus Arapiraca, Unidade Acadêmica Viçosa, Fazenda São Luis s/n, zona rural, Viçosa, AL 57700-000, Brazil. E-mail: sampaio.elizabeth@gmail.com

The objective of this study was to evaluate the in vitro efficacy of commercial disinfectants used in pre- and post-dipping, against Staphylococcus spp. isolated from milk originating from dairy cattle farms in the Wasteland and Forest Zone of Alagoas, Brazil. We used iodine $(0.57 \%)$, chlorhexidine $(2.0 \%)$, chlorine $(2.5 \%)$ and quaternary ammonium compound $(4.0 \%)$ at concentrations indicated, conventionally used as commercial disinfectants before and after dipping. We analyzed a total of 97 isolates of Staphylococcus spp. identified as S. aureus (16), coagulase positive Staphylococcus (7) and coagulase-negative Staphylococcus (74). The disinfectants were evaluated at three different times $(15 ", 30$ " and 60 "). We found that $56.3 \%$ of Staphylococcus aureus was sensitive to iodine, $68.8 \%$ to chlorine, $87.5 \%$ to chlorhexidine, and $37.5 \%$ to the compound of ammonia, in time 60 ". As for coagulase positive staphylococci (CPS), $100 \%$ of the isolates was resistant to chlorhexidine, $85.7 \%$ to the ammonia compound, $57.1 \%$ to chlorine, and $42.9 \%$ iodine, in time 60 ". Regarding coagulase negative staphylococci (CNS), 91.9\% was sensitive to chlorhexidine, $70.3 \%$ to chlorine, $66.2 \%$ to iodine, and $24.3 \%$ the ammonium compound, at time 60 ". It is concluded from this study that the greatest disinfectant activity in vitro was with chlorhexidine and chlorine for S. aureus, with iodine and chlorine for SCP, and with chloride and chlorhexidine for SCN. Due to variations in the sensitivity and resistance profile found, it is necessary for regular assessments of the effectiveness of disinfectants used on the farms, to observe the effectiveness of the product and thus ensure the control of mastitis in the herd.
\end{abstract}

INDEX TERMS: Desinfection, microorganisms, Staphylococcus spp., mastitis control.

\footnotetext{
${ }^{1}$ Recebido em 6 de julho de 2012.

Aceito para publicação em 9 de outubro de 2012.

${ }^{2}$ Universidade Federal de Alagoas, Campus Arapiraca, Unidade de Viçosa, Fazenda São Luiz s/n, Zona Rural, Viçosa, AL 57700-000, Brasil. *Autor para correspondência: sampaio.elizabeth@gmail.com

${ }^{3}$ Unidade Acadêmica de Garanhuns, Universidade Federal Rural de Pernambuco (UFRPE), Av. Bom Pastor s/n, Boa Vista, Garanhuns, PE 55296901, Brasil.

${ }^{4}$ Departamento de Medicina Veterinária, UFRPE, Av. Dom Manoel de Medeiros s/n, Dois Irmãos, Recife, PE 52171-900, Brasil.
}

RESUMO.- Objetivou-se com esse estudo avaliar a eficácia in vitro de desinfetantes comerciais utilizados no pré e pós-dipping, frente a Staphylococcus spp. isolados do leite de vacas procedentes de propriedades leiteiras do Agreste e Zona da Mata do Estado de Alagoas. Foram utilizados iodo $(0,57 \%)$, clorexidine $(2,0 \%)$, cloro $(2,5 \%)$ e composto de amônio quaternário $(4,0 \%)$, nas concentrações indicadas, como desinfetantes comerciais usados convencionalmente no pré e pós-dipping. Analisou-se um total de 97 isolados 
de Staphylococcus spp. identificados como S. aureus (16), Staphylococcus coagulase positiva (7) e Staphylococcus coagulase negativa (74). Os desinfetantes foram avaliados em três tempos distintos (15", 30" e 60"). Observou-se que $56,3 \%$ de Staphylococcus aureus foram sensíveis ao iodo, $68,8 \%$ sensíveis ao cloro, $87,5 \%$ à clorexidine e $37,5 \%$ ao composto de amônia no tempo de 60". Quanto aos Staphylococcus coagulase positiva (SCP), $100 \%$ dos isolados foram resistentes ao clorexidine, $85,7 \%$ ao composto de amônio, $57,1 \%$ ao cloro, e 42,9 resistentes ao iodo no tempo de 60". Em relação aos Staphylococcus coagulase negativa (SCN) foi observado $91,9 \%$ de sensibilidade ao clorexidine, $70,3 \%$ sensíveis ao cloro, $66,2 \%$ ao iodo e $24,3 \%$ sensíveis ao composto de amônio no tempo de 60 ". Conclui-se com esse estudo que a maior atividade desinfetante in vitro foi verificada para clorexidine e cloro frente aos $S$. aureus, iodo e cloro para os SCP e clorexidine e cloro para os SCN. Devido às variações no perfil de sensibilidade e resistência encontradas, é necessária a avaliação regular da eficiência dos desinfetantes usados nas propriedades, com o intuito de observar a eficácia do produto e assim garantir o controle da mastite no rebanho.

TERMOS DE INDEXAÇÃO: Desinfecção, microorganismos, Staphylococcus spp., controle da mastite.

\section{INTRODUÇÃO}

A mastite é caracterizada por um processo inflamatório da glândula mamária relacionado a agressões físicas, químicas, térmicas ou microbianas, sendo que $90 \%$ das mastites são causadas por bactérias. Além destes patógenos, fungos, leveduras, algas e vírus também podem estar envolvidos na etiologia da doença, porém a ocorrência é baixa (Tozzett et al. 2008).

Estudos epidemiológicos sobre a etiologia da mastite bovina revelam que os microrganismos de origem contagiosa são os mais prevalentes e entre estes, o gênero Staphylococcus destaca-se por possuir maior frequência em casos clínicos e subclínicos da doença, sendo Staphylococcus aureus a espécie de maior relevância para a indústria leiteira (Zschock et al. 2000).

Diversas medidas sanitárias devem ser adotadas durante o processo de ordenha para minimizar a transmissão de agentes causadores de mastites que podem ser transferidos ao leite depreciando sua qualidade microbiológica (Amaral et al. 2004).

0 método convencional de controle de mastite durante a ordenha consiste basicamente na lavagem dos tetos com água e assepsia com produtos químicos com ação antimicrobiana como cloro, iodo ou quaternário de amônio (Yokoya \& Martins 2009). Variações no perfil de sensibilidade e resistência dos microorganismos envolvidos nos processos infecciosos da glândula mamária de animais de produção leiteira podem comprometer os programas de controle da mastite bovina causada por Staphylococcus spp. (Medeiros et al. 2009).

0 uso apropriado de agentes desinfetantes tem como objetivo reduzir suficientemente a população de microorganismos patogênicos e evitar a potencial disseminação de agentes infecciosos. Como não existe um agente desinfetante ideal, deve-se ter em mente algumas considerações para a escolha do desinfetante apropriado, tais como possuir amplo espectro de ação; ser atóxico e não irritante aos tecidos humano e animal; apresentar estabilidade na pele e ter custo acessível (Pedrini \& Margatho 2003).

Objetivou-se com esse estudo avaliar a eficácia in vitro de desinfetantes comerciais utilizados no pré e pós-dipping, frente a Staphylococcus spp. isolados do leite de vacas procedentes de propriedades leiteiras do Agreste e Zona da Mata do Estado de Alagoas.

\section{MATERIAL E MÉTODOS}

O estudo foi realizado em oito propriedades de exploração leiteira do Agreste e Zona da Mata do Estado de Alagoas. Foram estudados 97 isolados de Staphylococcus spp. isolados do leite de vacas com mastite subclínica. Os rebanhos constituam-se de animais de várias raças, idades e que se encontravam em diferentes estágios de lactação, criados em sistema semi-intensivo, com sistema de ordenha manual.

As amostras de leite foram colhidas após prévia lavagem do teto com água e sabão, secagem com papel toalha e anti-sepsia do óstio do teto com álcool a $70^{\circ} \mathrm{GL}$. Coletaram-se aproximadamente $5 \mathrm{~mL}$ de leite, em tubos esterilizados e previamente identificados com o nome ou número do animal e quarto mamário, enviados sob refrigeração em caixas de material isotérmico contendo gelo reciclável, para a realização do exame microbiológico no Laboratório.

Alíquotas de leite foram semeadas, em placas de Petri contendo ágar-base enriquecido de $5 \%$ de sangue de ovino desfibrinado. As placas foram incubadas em estufa bacteriológica a $37^{\circ} \mathrm{C}$ e as leituras foram realizadas 24 e 48 horas após a incubação. Para a identificação das bactérias isoladas, foram observadas as características morfológicas das colônias como tamanho, tipo, coloração e presença de hemólise e ao microscópio foram observadas a disposição das células e características morfotintoriais ao Teste de Gram (Carter 1988).

Para identificação dos Staphylococcus spp. foram utilizadas as seguintes provas bioquímicas: teste da catalase (Anvisa 2011), produção de coagulase livre em tubo (Silva 1997), teste de produção de acetoína e fermentação da glicose (anaerobiose) (Mc Faddin 1980).Após a realização dos testes, os isolados foram classificados em Staphylococcus aureus, quando positivo em todos os testes, Staphylococcus coagulase positivo (SCP), quando positivo para a produção da coagulase, fermentação da glicose em anaerobiose, mas negativa na produção de acetoína e em Staphylococcus coagulase negativa (SCN) quando negativo para a produção de coagulase e positivo para os demais testes.

Para avaliar a ação dos desinfetantes utilizados no pré e pós-dipping foram utilizadas os seguintes princípios ativos: iodo na concentração de $(0,57 \%)$, clorexidine $(2,0 \%)$, cloro $(2,5 \%)$ e composto de amônia quaternária $(4,0 \%)$, sendo as diluições realizadas conforme orientação dos fabricantes. Para a análise foram preparadas suspensões bacterianas homogêneas de solução salina estéril (5,5mL) correspondendo ao tubo 1 da escala de McFarland. A suspensão foi constituída pela solução desinfetante $(0,8 \mathrm{~mL})$ diluída de acordo com o fabricante e o leite estéril $(0,2 \mathrm{~mL})$. Posteriormente, adicionou-se a suspensão bacteriana $(1,2 \mathrm{~mL})$ e cronometrou-se os tempos (15", 30" e 60") de exposição para então realizar o repique em caldo $\mathrm{BHI}$. A mistura foi incubada a $37^{\circ} \mathrm{C}$ durante 24 horas para observação da turvação do meio, formação de película na superfície ou de precipitado no fundo dos tubos. Após a incubação, a suspensão foi repicada em meio sólido (ágar 
sangue) para confirmação da presença ou ausência do microrganismo testado frente aos diferentes desinfetantes e tempo de exposição. A ausência do crescimento bacteriano nas placas indicou a eficácia do produto em questão (Costa et al. 1998).

Foi realizada uma análise estatística descritiva determinando as frequências relativas e absolutas dos tratamentos, posteriormente, realizou-se uma análise univariada das variáveis de interesse através do teste de qui-quadrado de Pearson ou exato de Fisher, quando necessário. 0 programa SPSS for Windows, versão 18,0 - Statistical Package for the Social Science, foi utilizado para a execução dos cálculos estatísticos.

\section{RESULTADOS}

Os resultados da ação dos desinfetantes iodo, cloro, clorexidine e composto de amônio quaternário, utilizados no pré e pós-dipping, frente a Staphylococcus aureus, SCN e SCP estão descritos nas tabelas 1, 2 e 3. 0 perfil de sensibilidade de $S$. aureus frente ao iodo nos tempos de 15", 30" e 60" foi de $31,3 \%$, 43,8 e 56,3\%, respectivamente. Quanto ao cloro, observou-se, que $62,5 \%, 62,5 \%$ e $68,8 \%$ foram sensíveis no mesmo período de tempo citado. Já para a clorexidine, $87,5 \%$ foram sensíveis em todos os tempos testados. Com relação ao composto de amônio, 6,3\%, 12,5\% e 37,5\% foram sensíveis nesses tempos.

Com relação ao SCP, observaram-se alto percentual de resistência a clorexidine e ao composto de amônio quaternário. 0 perfil de resistência dos SCP ao iodo foi de $71,4 \%$, $57,1 \%$ e $42,9 \%$, nos tempos de 15 ", 30 " e 60 " respectivamente, e ao cloro foi de $57,1 \%$ nos três tempos estudados.

0 perfil de sensibilidade dos SCN frente ao iodo nos tempos 15", 30" e 60 " foi de 33,8\%, 45,9\% e 66,2\%, respectivamente. Para o cloro observou-se, que $64,9 \%, 66,2 \%$ e $70,3 \%$ foram sensíveis. Quanto ao clorexidine os isolados apresentaram 85,1\%, 90,5\% e 91,9\% de sensibilidade. Com relação ao composto de amônio observou-se 12,2\%, $16,2 \%$ e $24,3 \%$ foram sensíveis nos tempos estudados.

Quadro 1. Análise univariada da eficácia dos compostos utilizados como desinfetantes no pré e pós-dipping para o controle da mastite bovina causada por Staphylococcus aureus em propriedades leiteiras do Agreste e Zona da Mata de Alagoas, 2011

\begin{tabular}{|c|c|c|c|c|c|c|c|}
\hline \multirow{3}{*}{$\begin{array}{c}\text { Desinfetantes } \\
\text { Tempo }\end{array}$} & \multicolumn{6}{|c|}{ Microbiológico } & \multirow[t]{3}{*}{ Valor $\mathrm{p}$} \\
\hline & \multirow{2}{*}{$\begin{array}{c}\text { Positivo } \\
\text { FA }\end{array}$} & \multicolumn{3}{|c|}{ Negativo } & \multicolumn{2}{|c|}{ Total } & \\
\hline & & FR\% & FA & FR\% & FA & FR\% & \\
\hline \multicolumn{8}{|l|}{ Iodo } \\
\hline $15^{\prime \prime}$ & 11 & 68,8 & 5 & 31,3 & 16 & 100,0 & 0,362 \\
\hline $30 "$ & 9 & 56,3 & 7 & 43,8 & 16 & 100,0 & \\
\hline $60 "$ & 7 & 43,8 & 9 & 56,3 & 16 & 100,0 & \\
\hline \multicolumn{8}{|l|}{ Cloro } \\
\hline $15 ”$ & 6 & 37,5 & 10 & 62,5 & 16 & 100,0 & 0,913 \\
\hline $30 "$ & 6 & 37,5 & 10 & 62,5 & 16 & 100,0 & \\
\hline $60 "$ & 5 & 31,3 & 11 & 68,8 & 16 & 100,0 & \\
\hline \multicolumn{8}{|l|}{ Clorexidine } \\
\hline $15^{\prime \prime}$ & 2 & 12,5 & 14 & 87,5 & 16 & 100,0 & 1,000 \\
\hline $30 "$ & 2 & 12,5 & 14 & 87,5 & 16 & 100,0 & \\
\hline $60 "$ & 2 & 12,5 & 14 & 87,5 & 16 & 100,0 & \\
\hline \multicolumn{8}{|l|}{ Composto de Amônio } \\
\hline $15^{\prime \prime}$ & 15 & 93,8 & 1 & 6,3 & 16 & 100,0 & 0,057 \\
\hline $30 "$ & 14 & 87,5 & 2 & 12,5 & 16 & 100,0 & \\
\hline $60 "$ & 10 & 62,5 & 6 & 37,5 & 16 & 100,0 & \\
\hline
\end{tabular}

*Associação significativa ao nível 5\%.
Quadro 2. Análise univariada da eficácia dos compostos utilizados como desinfetantes no pré e pós-dipping para o controle da mastite bovina causada por Staphylococcus coagulase positiva em propriedades leiteiras do Agreste e Zona da Mata de Alagoas, 2011

\begin{tabular}{|c|c|c|c|c|c|c|c|}
\hline \multirow{3}{*}{$\begin{array}{l}\text { Desinfetantes } \\
\text { Tempo }\end{array}$} & \multicolumn{6}{|c|}{ Microbiológico } & \multirow[t]{3}{*}{ Valor $\mathrm{p}$} \\
\hline & \multirow{2}{*}{$\begin{array}{c}\text { Positivo } \\
\text { FA }\end{array}$} & \multicolumn{3}{|c|}{ Negativo } & \multicolumn{2}{|c|}{ Total } & \\
\hline & & FR\% & FA & FR\% & FA & FR\% & \\
\hline \multicolumn{8}{|l|}{ Iodo } \\
\hline $15^{\prime \prime}$ & 5 & 71,4 & 2 & 28,6 & 7 & 100,0 & 0,558 \\
\hline $30 "$ & 4 & 57,1 & 3 & 42,9 & 7 & 100,0 & \\
\hline $60 "$ & 3 & 42,9 & 4 & 57,1 & 7 & 100,0 & \\
\hline \multicolumn{8}{|l|}{ Cloro } \\
\hline $15^{\prime \prime}$ & 4 & 57,1 & 3 & 42,9 & 7 & 100,0 & 1,000 \\
\hline $30 "$ & 4 & 57,1 & 3 & 42,9 & 7 & 100,0 & \\
\hline $60 "$ & 4 & 57,1 & 3 & 42,9 & 7 & 100,0 & \\
\hline \multicolumn{8}{|l|}{ Clorexidine } \\
\hline $15^{\prime \prime}$ & 7 & 100,0 & - & - & 7 & 100,0 & $* *$ \\
\hline $30 "$ & 7 & 100,0 & - & - & 7 & 100,0 & \\
\hline $60 "$ & 7 & 100,0 & - & - & 7 & 100,0 & \\
\hline \multicolumn{8}{|l|}{ Composto de amônio } \\
\hline $15^{\prime \prime}$ & 7 & 100,0 & - & - & 7 & 100,0 & 0,350 \\
\hline $30 "$ & 7 & 100,0 & - & - & 7 & 100,0 & \\
\hline $60 "$ & 6 & 85,7 & 1 & 14,3 & 7 & 100,0 & \\
\hline
\end{tabular}

* Associação significativa ao nível 5\%; ** não foi possível realizar o teste.

Quadro 3. Análise univariada da eficácia dos compostos utilizados como desinfetantes no pré e pós-dipping para o controle da mastite bovina causada por Staphylococcus coagulase negativa em propriedades leiteiras do Agreste e Zona da Mata de Alagoas, 2011

\begin{tabular}{|c|c|c|c|c|c|c|c|}
\hline \multirow{3}{*}{$\begin{array}{c}\text { Desinfetantes } \\
\text { Tempo }\end{array}$} & \multicolumn{6}{|c|}{ Microbiológico } & \multirow[t]{3}{*}{ Valor $\mathrm{p}$} \\
\hline & \multirow{2}{*}{$\begin{array}{c}\text { Positivo } \\
\text { FA } \\
\end{array}$} & \multicolumn{3}{|c|}{ Negativo } & \multicolumn{2}{|c|}{ Total } & \\
\hline & & FR\% & FA & FR\% & FA & $\mathrm{FR} \%$ & \\
\hline \multicolumn{8}{|l|}{ Iodo } \\
\hline $15^{\prime \prime}$ & 49 & 66,2 & 25 & 33,8 & 74 & 100,0 & $<0,001$ \\
\hline $30 "$ & 40 & 54,1 & 34 & 45,9 & 74 & 100,0 & \\
\hline $60 "$ & 25 & 33,8 & 49 & 66,2 & 74 & 100,0 & \\
\hline \multicolumn{8}{|l|}{ Cloro } \\
\hline $15^{\prime \prime}$ & 26 & 35,1 & 48 & 64,9 & 74 & 100,0 & 0,767 \\
\hline $30 "$ & 25 & 33,8 & 49 & 66,2 & 74 & 100,0 & \\
\hline $60 "$ & 22 & 29,7 & 52 & 70,3 & 74 & 100,0 & \\
\hline \multicolumn{8}{|l|}{ Clorexidine } \\
\hline $15^{\prime \prime}$ & 11 & 14,9 & 63 & 85,1 & 74 & 100,0 & 0,375 \\
\hline $30 "$ & 7 & 9,5 & 67 & 90,5 & 74 & 100,0 & \\
\hline $60 "$ & 6 & 8,1 & 68 & 91,9 & 74 & 100,0 & \\
\hline \multicolumn{8}{|l|}{ Composto de amônio } \\
\hline $15^{\prime \prime}$ & 65 & 87,8 & 9 & 12,2 & 74 & 100,0 & 0,141 \\
\hline $30^{\prime \prime}$ & 62 & 83,8 & 12 & 16,2 & 74 & 100,0 & \\
\hline $60^{\prime \prime}$ & 56 & 75,7 & 18 & 24,3 & 74 & 100,0 & \\
\hline
\end{tabular}

* Associação significativa ao nível 5\%.

\section{DISCUSSÃO}

Os resultados obtidos neste estudo indicaram maior atividade desinfetante in vitro do clorexidine e cloro para os Staphylococcus aureus, iodo e cloro para os SCP e clorexidine e cloro para os SCN. Em trabalho semelhante, Medeiros et al. (2009), estudando sobre a eficácia de desinfetantes comerciais utilizados no pré e pós-dipping frente amostras de Staphylococcus spp. isoladas de mastite bovina encontraram o iodo e clorexidine com maior atividade desinfetante para Staphylococcus aureus e iodo com melhor eficácia para SCP. 
De acordo com Fonseca \& Santos (2000), os melhores resultados nos pós-dipping têm sido obtidos com as seguintes concentrações: iodo $0,7-1,0 \%$, clorexidine $0,5-1,0 \%$ e cloro $0,3-0,5 \%$ ( $4 \%$ hipoclorito de sódio). No pré-dipping, os produtos tradicionalmente utilizados são o hipoclorito de sódio a $2 \%$, iodo a $0,3 \%$ e clorexidine a $0,3 \%$. Em ambos os casos deve-se fazer a imersão completa dos tetos (Santos \& Fonseca 2006).

A função principal da desinfecção dos tetos durante e após a ordenha é reduzir a população de microorganismos presentes. Isso é conseguido pelo uso de agentes desinfetantes, como a solução de iodo, cloro e amônio quaternário. 0 tratamento com desinfetantes à base de iodo, clorexidine e cloro (hipoclorito de sódio), são comumente utilizados nas propriedades rurais para o controle de população de microorganismos dos tetos nas ordenhas, diminuindo no pré-dipping a contaminação, reduzindo em até $50 \%$ a taxa de novas infecções causadas por patógenos (Santos \& Fonseca 2007).

O clorexidine apresentou ação desinfetante para Staphylococcus aureus e SCN, e resistência aos SCP. O clorexidine é bastante utilizado para o tratamento de infecções superficiais de tetos em vacas devido ao seu efeito cumulativo e contínuo, permanecendo na pele no mínimo por seis horas, além disso, atua na presença de matéria orgânica, é de fácil aplicação e econômico (Spinosa et al. 2002).

Foram encontrados resultados satisfatórios para o cloro neste estudo. 0 uso do cloro como agente desinfetante é prática comum nas propriedades leiteiras do Brasil, uma vez que o produto apresenta baixo custo. Entretanto tem como desvantagem sua menor estabilidade, além da não observação das recomendações e critérios de uso pelos produtores (Amaral et al. 2004).

0 iodo apresentou ação desinfetante inferior a clorexidine e o cloro. Soluções de iodo devem ser utilizadas em imersão de tetos em baixas concentrações $(0,5 \%$ ou menos), uma vez que soluções a $1 \%$ podem deixar resíduo no leite (Jones 1998).

Os resultados obtidos para o amônio quaternário revelaram grande resistência dos microorganismos estudados a este desinfetante. Medeiros et al. (2009) avaliando o perfil de sensibilidade de $S$. aureus frente ao composto de amônio quaternário a $4 \%$, obtiveram melhores resultados quando este microrganismo ficou exposto ao desinfetante por 30 ", 60 "e 300 ", com $80,0 \%, 80,0 \%$ e $82,2 \%$ de sensibilidade, respectivamente. Já para os SCP, o perfil de sensibilidade foi melhor nos tempos 60 " e $300 "$, com $81,8 \%$ e $90,9 \%$ de eficácia, respectivamente (Medeiros et al. 2009).

Infelizmente, a maioria dos produtos disponíveis para a desinfecção de tetos no mercado brasileiro não passou por protocolos de testes reconhecidos internacionalmente e que possam ser comparados entre si quanto a sua eficiência (Santos 2000). A avaliação periódica dos desinfetantes utilizados nas propriedades é importante, pois muitos não se mostraram eficazes para controlar os microorganismos mais prevalentes (Costa et al. 1998).

\section{CONCLUSÃO}

Conclui-se com esse estudo que a maior atividade desinfetante in vitro foi verificada para clorexidine e cloro frente a Staphylococus aureus, iodo e cloro para os SCP e clorexidine e cloro para SCN. Devido às variações no perfil de sensibilidade e resistência encontradas, é necessária avaliar regularmente a eficiência dos desinfetantes usados nas propriedades, com o intuito de verificar a eficácia do produto e assim garantir o controle da mastite no rebanho.

\section{REFERÊNCIAS}

Amaral L.A., Isa H., Dias L.T., Junior O.D.R. \& Filho A.N. 2004. Avaliação da eficiência da desinfecção de teteriras e tetos no processo de ordenha mecânica de vacas. Pesq. Vet. Bras. 24(4):173-177.

Brasil 2011. Detecção e Identificação de Bactérias de Importância Médica: Módulo V. Agência Nacional de Vigilância Sanitária (ANVISA), Brasília.

Carter G.R. 1988. Fundamentos de Bacteriologia e Micologia Veterinária. Roca, São Paulo. 250p.

Costa E.O. 1998. Importância da mastite na produção leiteira do Brasil. Revta Educ. Contin. CRMV-SP 1(1):3-9.

Fonseca L.F.L. \& Santos M.V. 2000. Qualidade do Leite e Controle da Mastite. Lemos Editorial, São Paulo. 175p.

Hosmer D.W. \& Lemeshow S. 1989. Applied Logistic Regression. John Wiley and Sons, New York. 241p.

Jones G.M. 1998. Milking practices recommended to assure milk quality and prevent mastitis. Dairy Science, Virginia Cooperative Extension, p.404-227.

McFaddin J.F. 1980. Biochemical Test for Identification of Medical Bacteria. William and Wilkins, Baltimore. $527 \mathrm{p}$.

Medeiros E.S. 2009. Avaliação in vitro da eficácia de desinfetantes comerciais utilizados no pré e pós-dipping frente amostras de Staphylococcus spp. isoladas de mastite bovina. Pesq. Vet. Bras. 29(1):71-75.

Pedrini S.C.B. \& Margatho L.F.F. 2003. Sensibilidade de microrganismos patogênicos isolados de casos de mastite clínica em bovinos frente a diferentes tipos de desinfetantes. Arqs Inst. Biológico, São Paulo, 70(4):391-395.

Santos M.V. 2000. A Importância da avaliação de desinfetantes para tetos. Artigos Técnicos - Qualidade do Leite. Brasil. Disponível em <http:// www.milkpoint.com.br/artigos-tecnicos/qualidade-do-leite/a-importancia-da-avaliacao-de-desinfetantes-para-tetos-16171n.aspx> Acesso em 29 mai. 2012.

Santos M.V. \& Fonseca L.F.L. 2006. Estratégias para Controle de Mastite e Melhoria da Qualidade do Leite. Editora Manole, Barueri. 314p.

Santos M.V. \& Fonseca L.F.L. 2007. Manejo de Ordenha visando o Controle de Mastite e a Melhoria da Qualidade do Leite. Estratégias para Controle de Mastite e Melhoria da Qualidade do Leite. 1aㅡ ed. Editora Manole, Barueri, p.78-94.

Silva N., Junqueira V.C.A. \& Silveira N.F.A. 1997. Manual de Métodos de Análise Microbiológica de Alimentos. Varela, São Paulo. 295p.

Spinosa H.S., Gorniak S.L. \& Bernadini M.M. 2002. Farmacologia Aplicada à Medicina Veterinária. Guanabara Koogan, Rio de Janeiro. 489p.

Tozzetti D.S., Bataier M.B.N. \& Almeida L.R. 2008. Prevenção, controle e tratamento das mastites bovinas: revisão de literatura. Famed, Garça, SP.

Yokoya E. \& Martins M.F. 2009. Controle de infecções intramamárias no gado leiteiro usando as propriedades antibacterianas e cicatrizantes do muco de escargot Achatina fulica sp. no pré e pós-dipping. Dissertação de Mestrado em Nutrição e Produção Animal, Faculdade Medicina Veterinária e Zootecnia, Universidade de São Paulo, Pirassununga, SP. 70p.

Zschöck M., Botzler D., Blöcher S., Sommerhäusen J. \& Hamann H.P. 2000. Detection of genes for enterotoxins (ent) and toxic shock syndrome toxin-1 (tst) in mammary isolates of Staphylococcus aureus by polymerase-chain-reaction. Int. Dairy J. 10:569-574. 